\title{
LXXXV. On the smelting of tin ores in Cornwall and Devonshire
}

\author{
John Taylor Esq.
}

To cite this article: John Taylor Esq. (1822) LXXXV. On the smelting of tin ores in Cornwall and Devonshire, Philosophical Magazine Series 1, 59:290, 417-424, DOI: 10.1080/14786442208652766

To link to this article: http://dx.doi.org/10.1080/14786442208652766

曲 Published online: 29 Jul 2009.

Submit your article to this journal $₫$

Џll Article views: 4

Q View related articles $\asymp$ 
or turf four inches thick, employing 3,824 horses, and 5,843 men, supposing it had been completed in one day.

In order to give employment to the poor of this neighbourhood, I contracted with five different persons; the whole was completed in August, many difficulties retarding it, from the unvsual quantity of rain during the summer months. On the 29th of May, a violent storm of wind raised the tide, and swept away 1800 yards of material, which would have totally discouraged the contractors, who had no property, and could not have sustained the loss, had I not reimbursed them. I am thankful.to say, the high tides in September and October have not made the slightest impression, and the whole of the work carries with it every appearance of stability. I apologize, sir, for the length of this communication; the desire expressed in the rules of the Society, that a detailed account should be given of works of this kind, must plead my excuse. I am, sir, \&c. \&c.

\section{Edward Dawson.}

The equinoctial tides in September were the highest in the last twenty-four years.

\section{Certificates.}

November 10, 1820.

This is to certify, that Edward Dawson, of Aldcliffe Hall, has, during the summer of the present year, effectually inclosed and secured from the orerflow of the tide, all that tract of land, near Lancaster, called Aldcliffe Marsh.

\section{R. Atkinson,}

One of His Majesty's Justices of the Peace for the County l'alatine of Lancaster.

November $10,1820$.

I do hereby certify, that Edward Dawson, of Aldeliffe Hall, has, during the summer of the present year, inclosed and effectually secured from the overflow of the sea, all that tract of land, near Lancaster, known by the name of Aldeliffe Marsh.

Thomas Bowes,

Deputy Lieutenant for the County of Lancaster.

LXXXV. On the Smelting of Tin Ores in Cornwall and Devonshire. By JoHn 'TAyLoR, Esq. Treasurer of the Geological Society*.

As I am not aware that the treatment of tin ores, or the mode of sneelting them, has been recently described, and as the practice is confined to a certain district, it may be acceptable to the Society to have some account of the processes now used in Cornwall aind Devon.

* From the Transactions of the Geological society.

Vol. 59. No.290. June 152\%. 
Tin ores are found in two kinds of deposits; first in veins accompanied by various other minerals; and, secondly, in alluvial matter in detached fragments.

It is usual in Cornwall not to apply the word ore to the oxide of tin, but to distinguish it, when in that state, by the term black tin, in contradistinction to white tin, which appellation is applied to it when smelted and in the metallic state.

The two kinds of tin ore above mentioned are, therefore, generally known by the names of mine tin and stream tin ; and as they are for the most part smelted separately, and by different means, and as the metal produced from them is different as to its purity, it may be essential to point out the causes from which this diversity seems to arise.

Mine tin is, as I have mentioned, the produce of veins, and is raised with a mixture of all the substances which unusually accompany it. There are, not unfrequently, copper ores, pyrites, wolfram, micicenus iron, \&c. and the separation of these, as also of the earthy matrix, is the object of various processes of dressing, which are conducted with the greatest care, and require a considerable portion of labour.

Whether, in a country where fuel for smelting is on the whole very cheap, it might not be cecononical to diminish the labour of dressing, and, by leaving more to be done in the furnace, reduce the expense of the former operations, is a question that $\mathbf{I}$ have never submitted to a direct experiment, though I conceive it to be one worthy of trial. The various earths may be quickly separated by fusion, as in the case of copper ores, which are now always smelted with a large mixture of the different kinds of spar in which they are found, all of which is easily run off by the fire, and the scoria or slag separated from the metallic part.

The fusibility of tin offers a mode by which it may be separated from an alloy of most other metals with which it is found to exist in veins, as lead and zinc ores are seldom mixed with it. This property is now made ise of to a certain extent in refining tin, and might probably be taken advantage of still further, so as to avoid some of the charges incurred in dressing the ore.

The metal produced from mine tin is always of inferior quality, owing to the mixture of other metals, and which it is prohable could not by any mode be entirely got rid of; it is known in commerce by the name of common or block tin, and the quantity forms a large proportion of the whole that is brought to market.

Stream tin is found in the lowest stratum of alluvial matter, in the bottoms of deep valleys, or places where a considerable deposit of mud, sand, and gravel, has been made by the action of water; it is often discovered occupying a thin bed incumbent on 
the rock, and covered by an overlurden, as the streamers call it, which is sometimes from 20 to 70 feet thick. The tin is in rounded fragments, sometimes as large as walnuts, but more generally in the state of small gravel, and even of fine sand; it is imbedded in loose matter, composed of the detritus of the rocks from which it may be supposed to have been separated.

The principal peculiarity of stream tin is the absence of any other metallic mixtures, except nodules of hematitic iron ore, which sometimes accompany it. This circumstance fits it for producing a very pure metal. This is not the place to speculate on the causes which have so completely freed these ores from substances with which they were in all probability originally combined, or to inquire whether it is to be attributed to mechanical action, or whether it has been effected by decomposition; but it may be remarked that, besides the hematite already mentioned, only the indestructible metals, and the oxide of tin, are now discovered existing in deposits of this nature.

The operations of dressing strean tin are simpler than those for mine tin. It is smelted also in a different manner, and produces a superior metal known by the name of grain till, which is principally used by the dyers, and for the finer purposes.

The processes for dressing mine tin are in many respects the same as are used for all other ores, but are subject to some variations, which are attributable to the following peculiarities.

1. Being for the most part found intimately dispersed throughout the matrix, the whole is necessarily pounded down to a very fine state, to admit of the perfect separation of the ores.

2. That heing unalterable by moderate degrees of heat, it admits of calcination, by which the specific gravity of the sulphurets or arseniats with which it is mixed, may be lessened, and a mode obtainer of rendering them more separable.

3. That the weight of tin ore being greater than most others, it is less liable to waste in the processes of washing, and, therefore, may be dressed so as to be nearly clean from all substances not actually adhering to it.

From the first of these peculiarities it follows, that all tin mines must be furnished with stamping-nills of sufficient power to bruise down the ores raised, which is generally done so as to produce a minute division of the whole, and on this account, formerly, the quantity and fall of water that could be applied to this purpose usually limited the quantity of ore that could be returned from a mine, or the whole was frequently carried to some spot favourable to the erection of water-wheels to be applied to this purpose. Within a few years steam-power has been applied to stamping-mills, and has tended to increase the supply of tin cres. Engines for this purpose, of considerable power, are

$$
3 \mathrm{G} 2
$$
working 
working with great effect at two of the largest tin mines in Cornwall, Wheal Vor and Great Huas; from which are now arising abundant returns of the metal, and where formerly it wouli heve been impossible to have produced it.

The state of division, or the size, as the tin dressers call it, is regulated by a plate of iron pierced with small holes, through which the whole passes from the stamping-mill, being washed through by a rapid stream of water conducted upon it for the purpose. This is a point of great importanee, and is regulated by the state of dissemination in which $\mathrm{E} v$ ary ore is found.

It is not the intention of this memoir to detail the processes of ùressing which are common to most ores, and, therefore, it may be sufficient to remark that, after being stamped, the tin ores are washed according to the usual mode, so as to separate the earthy mixture and as much of that of a metallic nature as is possible. All these operations are conducted with more than common care and accuracy; for, as tin ore holds such a large proportion of valuable metal, it is of course treated with every precaution to guard against waste.

Some metallic substances will be found, however, which, from their specific gravity approaching nearly to that of tin ore, or rather exceeding it, cannot be removed by any process of washing; these are mostly decomposable by a red heat, which the oxide of tin will bear without alteration. Therefore, after as much has been done as possible to render the ores clean on the dressing-floors, they are taken to the burning-house, which is furnished with small reverberatory furnaces, on the floor of which the ores are spread, and submitted to the action of a moderate and regular fire: they are frequently turned over by an iron rake to expose fresh surfaces, and a considerable volatilization of sulphur and arsenic takes place; the former seems principally to be consumed, and the latter is condensed by long horizontal lues constructed for this purpose. After the ores come from the burning-house, the process of dressing is completed by further washing, which is rendered easy by the alteration which has been produced in the relative weight of the substances.

Copper ore is not unfrequently present in these cases, and, as it is in part converted into sulphate of copper, the water which is first used is preserved, and a portion of copper obtained from it by means of iron.

The great specific gravity of the tin ore, as I have before remarked, renders it possible with care to subject it to many operations in dressing withont much waste; and they are, therefore, applied until the whole is generally so clean, as to yield a produce of metal equal to from 50 to 75 per cent. In this state they are sold by the miner to the smelter, who determines their 
value by assaying a sample, carefully taken from the whole quantity.

The furnaces for smelting mine tin are all of the common reverberating kind, and are of sufficient size to hold twelve to sixteen hundred weigltt of ore.

The charge is prepared by mixirg it with a proportion of stone coal, or Weich culm, to which is added a moderate quantity of slaked lime; these are turned over together and moistened with water, which prevents the too rapid action of the heated furnace, and which would otherwise volatilize some of the metal before fusion commenced.

The heat employed is a very strong one, and such as to bring the whole into perfect fusion; it is continued seven or eight hours, when the charge is ready to draw. For this purpose, the furnace is furnished with a tap-hole leading from the lowest part of the bottom, which, during the process, is stopped with clay or mortar, and under which is placed an iron kettle to receive the metal. The furnace has also a door at the end opposite the fre-place, throngh which the slag or scoria may be raked out from the surface, while the tin is flowing out, by unstopping the tap-hole.

They are thus divided, and the tin is laded into moulds, so as to form plates of a moderate size, and put by for a further refining. The slag, which rapidly hardens into a mass, is removed to a dressing-floor, where, being broken up and stamped, it is washed, and a quantity of tin taken from it, which is called Prillion, and which is afterwards smelted agrain.

No operation in smelting is more easy than that practised for tin ores, nor is there any one in which the reasons for the mode of treatment are so obvious. There are but two things to accomplish in this first process; to obtain perfect fusion of the carths so as to suffer the metal to separate easily from them, and to decompose the oxide of which the ore uniformly consists.

The addition of lime contributes to effect the former, and that of carbonaceous matter or coal completes the reduction of the ore. The separation of the metal from the earths then takes place in the usual way during fusion, by the difference in their specific gravities, the one precipitating to the bottom of the furnace, from whence it is drawn off by the tap-hole, and the other, floating on the surface, is removed in the manner $I$ have described.

The plates of tin, which are the produce of this smelting, are somewhat impure, and are more or less so according to the quality of the ore which has been used; they are reserved until a sufficient quantity of them is obtained to proceed with the refining, which is performed either in the sanic furnace, after oresmclting 
smelting is finished, or in a similar one, which may be reserved for the purpose.

All the processes for refining nietals in the fre must be performed by taking advantage of some property in which the metal operated on may differ from those with which it is alloyed, and which it is intended to separate from it. These differences may consist in the facility or difficulty of oxidation, in their tendency to volatilize, in the temperature required for fusion, or in their relative specific gravities.

Upon an attention to the two latter circumstances is founded the operation for refining tin. The substances which are most to be suspected in the produce of the first melting, and which it is desirable to separate, will probably be iron, copper, arsenic, tungsten from the wolfram, which the miners call mock-lead, and a portion of undecomposed oxides, sulphurets, or arseniates, and of some earthy matter or slag.

The furnace for refining is raised but to a very moderate degree of heat, and the plates of tin heing placed in it are suffered to melt very gradually, and the metal fows from the furnace at once into the kettle, which is now kept hot by a small fire placed beneath it. The more infusible substances will now be left in the furnace, and a further purification of the tin is obtained by agitating it in the kettle for some time by an operation which they call tossing: this is performed by a man with a ladle, who continues for some time to take up some of the melted metal, and pour it back into the kettle from such a height as to stir up the whole mass and put every part into motion.

When this is discontinued, the surface is carefully skimmed, and the impurities thrown up are removed ; these consist of such matters as are lighter than the tin, but which are suspended in it, and, being disengaged by the motion, find their way to the top. In general, the metal is at once laded into the moilds, after the tossing and skinming are completed; but the produce of impure and irony ores may yet require that the tin be divided as much as possible from the mixture which may yet remain. This may be effected in a great degree by keeping the mass in the kettle in a melted state, by which the parts which are heavier than the tin will sink to the bottom, and by leaving a proper portion behind, the tin will be materially improved.

The last operation is that of pouring the metal into moulds, which are usually formed of granite, and which are of such a size as to make it into pieces of somewhat more than three hundred weight each. These are called blocks, and are sent, according to the provisions of the Stannary laws, to be coined by the Duchy Officers; and it then comes to market under the name of Block Tin, or a certain part which bas been treated with more than conmon care is called Refined 'Tin.

The 
The making of grain tin from the ores from stream works is conducted in a manner altogether different, and remains to be described.

I have pointed out the purity of these ores, as regards their freedom from a mixture of other metals, and I do not think it important here to describe the mode of separating them by washing from the sand and gravel in which they are found, because the processes are very similar to those in use for dressing other ores. The stream tin is generally made very clean, and is carried in this state, to be sold for smelting, to establishments which are called blowing-houses, being thus distinguished from smeltinghouses in which mine tin is reduced, and the term is also descriptive of the process employed.

The reduction of the ores for grain tin is performed by blast furnaces, and the only fuel used is charcoal. This mode of smelting is exceedingly simple, and is probably the most ancient one, as would appear from relics sonetimes met with of furnaces of rude construction, and in some of which the wind alone seems to have been depended on for urging the fire.

The fumaces now in use are similar to those met with for smelting iron in foundries where the blast is used, and are formed by a cylinder of iron standing upon one end and lined with elay or loam. The upper end is open for receiving the fuel and ore, which are thrown alternately, and a liole at some distance from the bottom, at the back of the cylinder, is provided to almit the blast, and another, lower down and opposite to it, suffers the metal to flow out regularly as it is reduced.

A strong blast is kept up by bellows, or, in more improved works, by pistons working in cylinders, and the air is conducted by a proper pipe so as to blow into the orifice in the furnace.

The only purification it seems to require is to separate from it such substances as are mechanically suspended in it, and for this purpose it is laded into an iron pan or kettle, where the fusion is kept up by a gentle fire underneath, and a complete agitation of the mass is effected by plunging into the melted metal pieces of charcoal, which have been soaked in water, and, by means of an iron tool, keeping them at the bottom of the kettle. The water in the charcoal is rapidly converted into vapour, which rushing through the metal, gives it the appearance of rapid ebullition. After this is over, and the whole has rested some little time, the scum, which is thrown up to the surface, is takeu off; and the tin, which is peculiarly brilliant in appearance, is removed by ladles into proper moulds, to form the blocks in which it is generally sold.

Grain tin is, however, sometimes put into a different form by breaking it: for this purpose, the blocks are heated to such a 
degree as is known to render the metal brittle; they are then raised a considerable height from the ground, and, being suffered to fall, the whole divides into fragments, which assume a very peculiar appearance.

The smelting by a strong blast is injurious to metals that are volatilizable by heat, as they have in this mode no protection from the slag, which in reverberating furnaces floats on their surface, and protects them from oxidation and evaporation. The old practice of melting lead in what are called ore earths, is, on this account, giving way, and reverberating furnaces are coming into general use, by which the produce of metal from the ore is considerably increased. Tin, though volatile to a certain degree, is not affected by the process in any important manuer; but, as some flies off in white fumes, it is usual to construct a long horizontal fiue, which is made to communicate with and pass through a kind of chamber, in which a considerable part of these fumes is condensed and collected.

LXXXVI. Successful Result of an Experiment on Draining of Land. By John Christian Curwen, Esq. M.P.*

Dear Sir, - Inclosev I have the honour to transmit for the Society a paper on Draining; if it should be considered as worthy of the attention of the Society, I shall be greatly flattered.

I have left the country in great distress, and numbers of poor people out of employment. I hope to have the honour of paying my respects to you soon. I disposed of the rice you sent me into various hands. I have planted the wheat in my own garden. I am, sir, \&c. \&ce.

$$
\text { A. Airin, Esq. }
$$

Secretary, Ëc.

J. C. Curwen.

The Workington Hall, Jan. 17, 1821 . The encouragement given by the Society of Arts, for the improvement of agriculture, and every useful undertaking, emboldens me to submit to them the details of a work recently executed.

In the present state of the country, more important service cannot be rendered it, than suggestions for the profitable application of capital to labour.

Draining has universally been allowed to be the first and most essential step towards the permanent improvement of land. Fully as all writers are agreed upon this point, the cost that may

* From the Tranatations of the Society for the Encouragement of Arts, Manufactures, and Commerce, for 1821. The Thanks of the Society were roted to Mr. Curwen for this communication.

profitably 